4 Abe T, Misawa S, Nishioka K, Okuno T, Nakagome $\mathrm{Y}$. Formation of a ring chromosome 14 subsequent to the de novo 13/14 reciprocal translocation: a new cytogenetic evidence obtained by the nucleolus-organiser staining. Ann Genet (Paris) 1978;21:109-12.

5 Amarose AP, Dorus E, Huttenlocker PR, Lsarzar S. A ring 14 chromosome with deleted short arm. Hum Genet 1980;54:145-7.

6 Varela MA, Sternberg WH. Ring chromosomes in two infants with congenital malformations. J Med Genet $1969 ; 6: 334-41$.

7 Allderdice PW, Davis JG, Miller OJ, et al. The 13qdeletion syndrome. Am J Hum Genet 1969;21:499-512.

Requests for reprints to Dr R Schmidt, Department of Pediatrics, Albert Einstein College of Medicine, 1300 Morris Park Avenue, Bronx, New York 10461, USA.

\section{A 5;7, 5;12 double reciprocal translocation in a normal mother and a 5;7 translocation with a recombinant chromosome 5 in her normal child*}

SUMMARY A phenotypically normal mother had two apparently balanced translocations involving chromosomes 5,7 , and 12 . Her karyotype was $46, X X, t(5 ; 7)(5 ; 12)(\mathrm{p} 14 \mathrm{q} 34 ; \mathrm{p} 14 ; \mathrm{q} 21)$, while her daughter, who was also phenotypically normal, had inherited only one of the translocations. Her karyotype was $46, \mathrm{XX},-5,-7$, $+\operatorname{rec}(5) \mathrm{t}(5 ; 7)(\mathrm{q} 34 ; \mathrm{pl} 14) \mathrm{mat},+\operatorname{der}(7) \mathrm{t}(5 ; 7)$ (q34; p14)mat. The other was lost during a meiotic crossing over, giving the daughter an apparently balanced chromosome complement.

Many cases of single autosomal reciprocal translocations, but only a few double translocations, have been reported..$^{1-5}$

This report concerns a phenotypically normal female with two reciprocal translocations involving three chromosomes and her phenotypically normal daughter who inherited only one of these translocations.

\section{Case report}

The proband was a phenotypically normal 29-yearold woman referred to a gynaecological department in 1971 because of three spontaneous abortions in the 12 th to 16 th weeks of pregnancy.

*Partially supported by grants from The P Carl Petersen Foundation (B995) and The Danish Medical Research Council (512-4276).

Received for publication 25 September 1980
Cervical insufficiency was diagnosed and a cerclage applied. Conception occurred and the patient experienced an uncomplicated pregnancy until 8 weeks before term, when a caesarean section was performed owing to premature labour, and a liveborn girl of $1500 \mathrm{~g}$ was delivered. After treatment in the neonatal department, she thrived well and was described in 1977 by her general practitioner as normally developed, physically as well as mentally.

In 1973 and 1975, a cerclage was again applied. Each time the patient became pregnant, but aborted spontaneously in the 10th and 18th week, respectively.

A chromosome analysis was then performed on the patient, her husband, daughter, and mother. The patient had no contact with her biological father.

\section{CYTOGENETIC STUDIES}

Chromosome analysis was carried out on peripheral blood cultures using the GTG, QFQ, and RBA
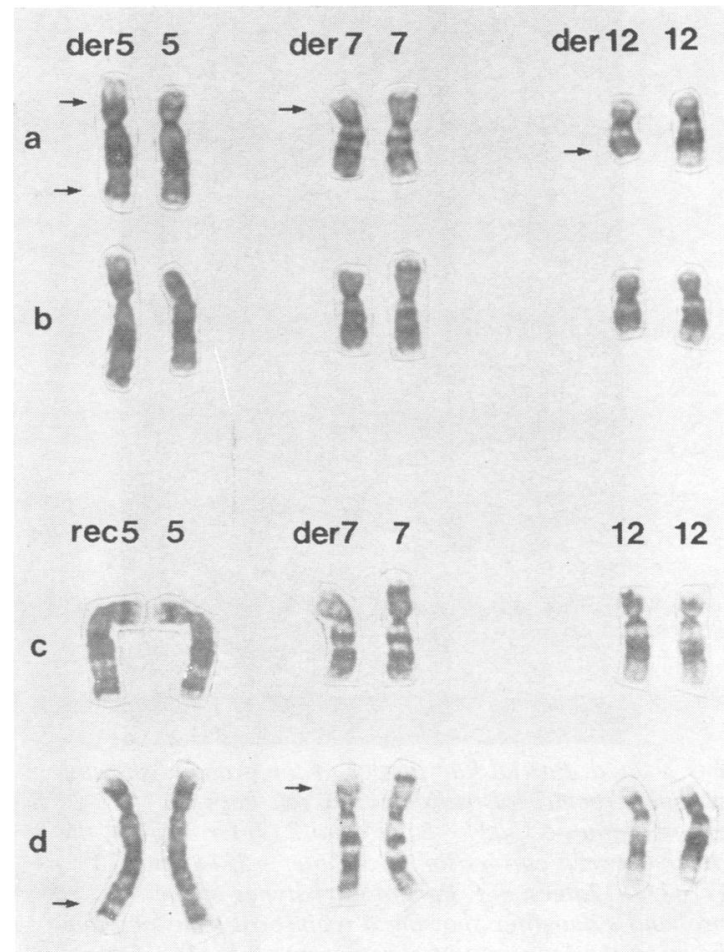

FIG $1 a, b$, partial karyotypes of the proband; $c, d$, partial karyotypes of the proband's daughter ( $G$ banding). The respective breakpoints are indicated on the figure. 
banding techniques. The mother and husband were found to have normal chromosome complements.

In the proband, two apparently balanced translocations were found (figs 1,2 ), one between the long arm of chromosome 5 and the short arm of chromosome 7 , and the other between the short arm of the same chromosome 5 and the long arm of chromosome 12.

According to the ISCN nomenclature, ${ }^{6}$ the karyotype was $46, \mathrm{XX}, \mathrm{t}(5 ; 7)(5 ; 12)(\mathrm{p} 14 \mathrm{q} 34 ; \mathrm{p} 14 ; \mathrm{q} 21)$, or $46, \mathrm{XX}, \mathrm{t}(5 ; 7)(5 ; 12)(7 \mathrm{pter} \rightarrow 7 \mathrm{p} 14:: 5 \mathrm{q} 34 \rightarrow 5 \mathrm{p} 14$ $:: 12 q 21 \rightarrow 12$ qter; $7 \mathrm{qter} \rightarrow 7 \mathrm{p} 14:: 5 \mathrm{q} 34 \rightarrow 5 \mathrm{qter} ; 12 \mathrm{pter}$ $\rightarrow 12 \mathrm{q} 21:: 5 \mathrm{p} 14 \rightarrow$ 5pter).

In the proband's daughter, only one translocation was found between the long arm of chromosome 5 and the short arm of chromosome 7 (fig $1 \mathrm{c}, \mathrm{d}$ and 2 e,f). This can only be explained by a meiotic crossing over having taken place somewhere in chromosome 5 between p14 and q34. The result was

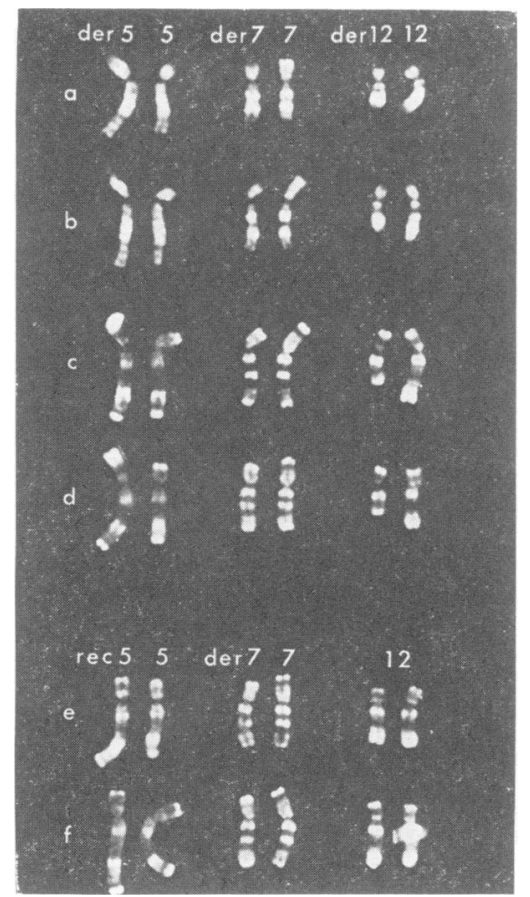

FIG $2 a-d$. Partial karyotypes of the proband showing a double reciprocal translocation, one between chromosomes $5(5 q 34 \rightarrow 5 q t e r)$ and $7(7 p t e r \rightarrow 7 p 14)$, the other between chromosomes 5 (5pter $\rightarrow 5$ p14) and 12 $(12 q 21 \rightarrow 12 q t e r) . e-f$. Partial karyotypes of the proband's daughter showing a reciprocal translocation between the long arm of chromosome $5(5 q 34 \rightarrow 5 q$ ter $)$ and the short arm of chromosome $7(7 p t e r \rightarrow 7 p 14)$. The short arm of the recombinant chromosome 5 and both chromosomes 12 are normal. a, $b Q$ banding; $c-f$ AO banding. a recombinant chromosome 5 , which the child $\stackrel{\overrightarrow{\mathbb{Q}}}{+}$ inherited from the mother together with $\operatorname{der}(7)$ and $\overrightarrow{\vec{F}}$ a normal chromosome 12 . The apparently balanced karyotype could be written as follows: $46, \mathrm{XX},-5$, 등 $-7,+\operatorname{rec}(5) \mathrm{t}(5 ; 7)$ (q34;p14)mat, $+\operatorname{der}(7) \mathrm{t}(5 ; 7)$ (q34; p14)mat, or $46, X X,-5,-7,+\operatorname{rec}(5)(5 p t e r \rightarrow 5 q 34)$ $:: 7$ p14 $\rightarrow 7$ pter $),+\operatorname{der}(7)(7 q t e r \rightarrow 7$ p14: $: 5 q 34 \rightarrow 5 q$ ter $)$.

\section{Discussion}

This case is remarkable, not only because the $\overrightarrow{\vec{\omega}}$ proband has a double reciprocal balanced translocation, but also because her phenotypically and genotypically normal child has a single balanced reciprocal translocation involving a recombinant $\vec{\infty}$ chromosome. Recombinant chromosomes are most + often caused by meiotic crossing over between $\omega_{0}$ normal and inverted chromosomes and will almost always result in unbalanced chromosome comple- $\frac{}{3}$ ments and phenotypically abnormal subjects.

The case causes some problems using the conventional ISCN nomenclature. If only the child, but $\frac{6}{c}$ not the mother, had been cytogenetically investi- $\stackrel{\oplus}{\oplus}$ gated, her karyotype would have been $46, X X, \vec{\oplus}$ $\mathrm{t}(5 ; 7)(\mathrm{q} 34 ; \mathrm{p} 14)$. Having also investigated the $\stackrel{\infty}{-}$ mother, the karyotype becomes $46, \mathrm{XX},-5,-7$, $+\operatorname{rec}(5) t(5 ; 7)(q 34 ; p 14),+\operatorname{der}(7) t(5 ; 7)(q 34 ; p 14) m a t . ~ O$ Although this karyotype is still balanced, it is written in a way and uses symbols (rec and der) primarily intended for unbalanced karyotypes. $\frac{O}{D}$ Independently segregating translocations have been $\stackrel{\varrho}{\Rightarrow}$ reported before. ${ }^{7}$ In a study of a large kindred with three cytogenetic markers, Jacobs et $a l^{4}$ for the first time showed cytogenetic evidence of meiotic crossing over in man, as children from a father with a balanced translocation involving one of the chromosomes $1(\mathrm{t}(1 ; \mathrm{C}))$, and a secondary constriction on the other chromosome 1 , inherited a 3 chromosome 1 with both the translocation and the secondary constriction.

To our knowledge, this is the first case illustrating two independently segregating translocations and at the same time showing evidence of a recombinant $\frac{D}{0}$ chromosome resulting from meiotic crossing over.

The proband's abortions were not examined $N$ cytogenetically, so it was not possible to determine $\mathrm{N}$ whether they were the result of chromosomal $N$ imbalance or of cervical insufficiency in the patient. $\omega$

ANN TABOR, * LENE KIELER JeNSEN, $\uparrow \underset{\sim}{0}$ Claes Lundsteen,* AND Erik Niebuhr $+\frac{0}{\varnothing}$ *Section of Clinical Genetics, Department of Gynecology and Obstetrics YA, 0 and Department of Pediatrics G, Rigshospitalet; $\dagger$ Department of Gynecology and Obstetrics, $\stackrel{\mathbb{\mathrm { D }}}{\mathrm{Q}}$ Slagelse Hospital; and $\ddagger$ Institute of Medical $\stackrel{\mathbb{\mathrm { Q }}}{\mathrm{Q}}$ Genetics, University of Copenhagen, Denmark. 


\section{References}

1 Bass HN, Sparkes RS. Two balanced translocations in three generations of a pedigree. J Med Genet 1979;16: 215-8.

2 Bell EF, Warburton D. Two reciprocal translocations associated with microcephaly and retardation. $J$ Med Genet $1977 ; 14: 141-2$.

3 Bijlsma JB, de France HF, Bleeker-Wagemakers LM, Dijkstra PF. Double translocation $\mathrm{t}(7 ; 12), \mathrm{t}(2 ; 6)$ : heterozygosity in one family. Hum Genet $1978 ; 40: 135-47$.

4 Jacobs PA, Buckton KE, Christie S, Newton M, Matthew D. A family with two translocations and a polymorphism involving chromosome No 14. J Med Genet 1974;11: 65-8.

${ }^{5}$ Prieto F, Badia L, Moreno JA, Barbero P, Asensi F. $10 \mathrm{p}$ - syndrome associated with multiple chromosomal abnormalities. Hum Genet $1978 ; 45: 229-35$.

6 ISCN. An international system for human cytogenetic nomenclature (1978). Cytogenet Cell Genet 1978;21: 309-404.

7 de Grouchy J, Finaz C, Roubin M, Roy J. Deux translocations familiales survenues ensemble chez chacune de deux soeurs, l'une équilibrée, l'autre trisomique partielle 10q. Ann Genet (Paris) 1972;15:85-92.

Requests for reprints to Dr A Tabor, Section of Clinical Genetics, Department of Gynecology and Obstetrics YA, Rigshospitalet, Blegdamsvej 9, 2100 Copenhagen $\varnothing$, Denmark.

\section{Tetraploidy in a liveborn infant with spina bifida and other anomalies}

SUMMARY Although tetraploidy of human chromosomes $(92, \mathrm{XXYY})$ has been described frequently in abortuses, only one example in a liveborn infant has previously been described. ${ }^{1}$ A second malformed infant with a complete tetraploid chromosome complement, who lived for 15 days, is reported. In addition to many of the malformations described in the first case, this infant also had a sacral myelomeningocele and skeletal anomalies. The probable origin of the tetraploidy was a failure of cytoplasmic cleavage at the first mitotic division of the fertilised ovum.

Although tetraploidy of human chromosomes $(92, X X Y Y)$ has been described frequently in abortuses, only one example in a liveborn infant has previously been described. ${ }^{1}$ We report here a second example, with some similar phenotypic effects, which are listed in the table.

* She has since this report had a second pregnancy monitored by amniocentesis, which showed a 46,XX fetus; $\alpha$-fetoprotein levels were normal.

Received for publication 8 August 1980
TABLE Features of liveborn human tetraploids

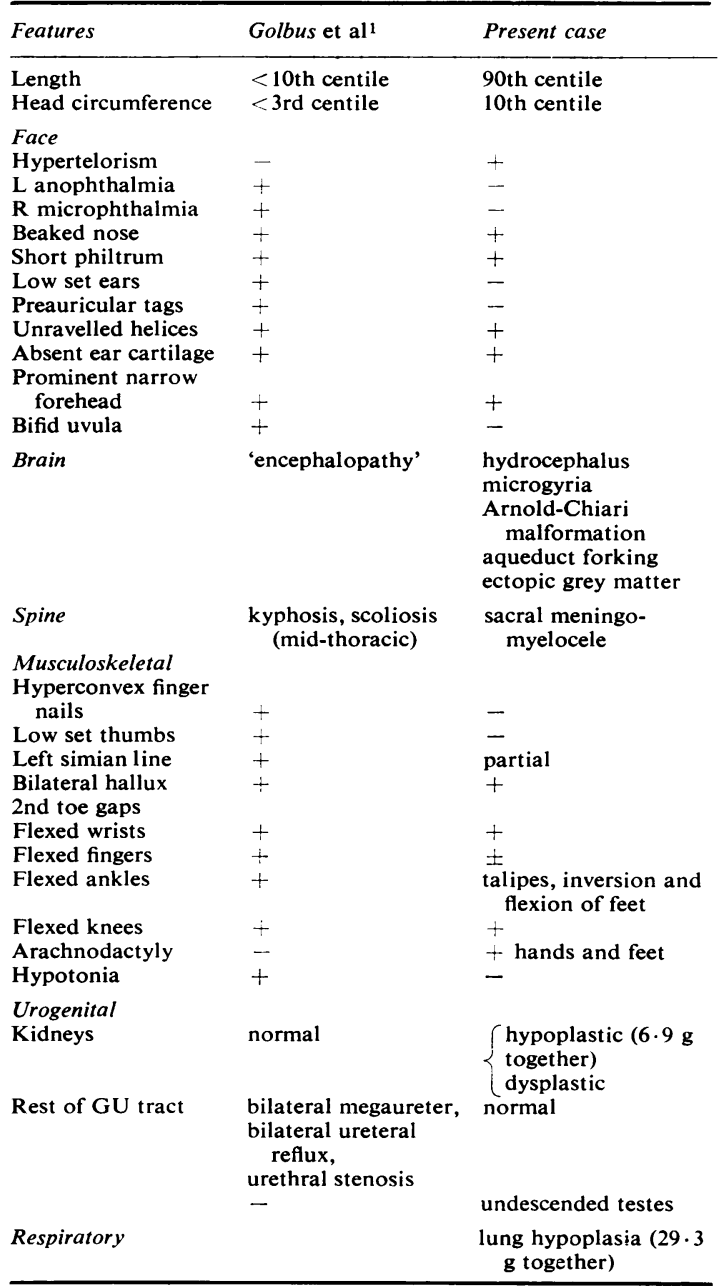

\section{Case report}

This child, born 17.3.79, was the first baby of healthy unrelated parents; the mother was 26 and the father 27 years old. There was no family history of any relevant birth defects except for a paternal second cousin with spina bifida (male). During the pregnancy the mother was well except for late toxaemia, for which she was admitted to hospital one week before labour was induced. During pregnancy there were no infections and no exposure to known toxic agents such as drugs, cigarettes, and $x$-rays. The mother's previous menstrual cycle had been normal ( 28 days) and the contraceptive pill had been stopped 6 months before conception.*

The baby was thought to be at term on dates, but 